\title{
Effectiveness of a structured clinical program in paediatric undergraduate training
}

\author{
D sa $\mathrm{S}^{1}$, Pinto DJV ${ }^{2}$, Bhat K. $\mathrm{G}^{3}$, Baliga B. $\mathrm{S}^{4}$, Joseph $\mathrm{N}^{5}$ \\ ${ }^{1}$ Dr Smitha D sa, ${ }^{2}$ Dr Deepak J V Pinto, ${ }^{3}$ Dr Kamalakshi G Bhat, ${ }^{4}$ Dr B. S Baliga, ${ }^{5}$ Dr Nitin Joseph. All affilaied with \\ Department of Paediatrics, Orthopedics and Community Medicine, Kasturba Medical College, Mangalore, Manipal \\ University, India.
}

Address for correspondence: Dr Smitha D’sa, Email: drsmithadsa@gmail.com

\begin{abstract}
Objective: To assess the effectiveness of a structured training program in Paediatrics during the clinical posting of final term undergraduates. Methods: 250 final term undergraduate students divided into 5 batches participated in the study. They were given a pretest questionnaire on specific topics and scored for a maximum of 10 . The answers were corrected by 2 different examiners. The overall scores were categorized as poor $(<5)$ average $(5$ to 7$)$ and good $(>7)$. A four week structured training program of 10 topics of Paediatrics was designed. It consisted traditional formats of teaching modules like general clinics, bedside clinics, ward rounds, procedures and therapeutic discussions. To maintain continuity and reinforce learning, a topic was selected as a theme of the day and various aspects of this topic were dealt with, during the interactions in the above modules. At the end of 4 weeks the post test (same questions and format of evaluation as pretest) was administered. The data was analyzed using Gamma test and McNemer's tests. P value of $<0.05$ was taken as statistically significant. Results: In the pre-test, 77.7\% scored poor and none of them had good scores. Post-test poor scores decreased to $8.9 \%$ and $23.13 \%$ had good scores. Astatistically significant improvement in the performance of the students' in the post-test was noted as compared to the pre-test. Conclusions: The structured training program which was used in this study resulted in significant improvement in the clinical knowledge of students.
\end{abstract}

Keywords: Structured training, Bedside clinic, General clinic, Pre-test, Post-test.

\section{Introduction}

Medical schools and teachers have a responsibility to create new knowledge and transfer this knowledge to the students in a way that addresses the social needs of the community [1]. Quality Paediatric education is required to provide best care for infants, children and adolescents by the medical professionals.

Due to the advances in technology and gadgets available new methods have been evolved in class room teaching of undergraduates for better transfer of knowledge. However, the teaching methodology and techniques in clinical settings in hospital has not seen much change and newer ways like simulation should be incorporated [2].

Pediatric education begins with designing the

Manuscript received: $4^{\text {th }}$ May 2016

Reviewed: $14^{\text {th }}$ May 2016

Author Corrected; $25^{\text {th }}$ May 2016

Accepted for Publication: $6^{\text {th }}$ June 2016 curriculum and syllabus which is appropriate for the needs of the community. The training program should enhance diagnostic and management skills of the students and in turn help in improving health care delivery.

There has been a recent trend to include objective structuredclinical examination scenarios in the clinical teaching paediatric training programs [3]. However, to our knowledge there has not been any attempt to structure various modules of clinical teaching and integrate their content to cover all important aspects of clinical paediatrics over a time frame of a single clinical undergraduate posting.

Hence we designed a time bound structured clinical program involving all the modules of clinical teaching and tried to assess the effectiveness of it in teaching paediatrics during the clinical posting of final MBBS 
students. The method of assessment using pretest and posttest has been well evaluated and is a very useful tool in assessment of student in achieving short-term learning objectives [4].

\section{Materials and methods}

The study was done in the department of Paediatrics from Kasturba Medical College, Mangalore where the students were posted for 4 weeks clinical posting during the final MBBS in the year 2015. 250 students were divided into 5 batches of 50 students each. Each batch underwent a 4 week structured training program. Each batch was divided into 5 units of 10 students.

A pretest questionnaire covering 10 topics of Pediatrics consist of growth and development, nutrition anthropometry, immunization, social paediatrics, newborn care and systemic Pediatric topics of Cardiology, Haematology, GIT and Respiratory system were given. They were told to answer the multiple choice questions by marking the correct answer. A 4 week structured training program in Paediatrics was designed. It consists of traditional formats of teaching modules like general clinics bedside clinics, ward rounds, procedures and therapeutic discussions. To maintain continuity and focus, a topic was selected as a theme of the day. General clinics consisted of case discussion by the batch of 50 students involving the theme topic for the day. Teaching staff members ensured availability of clinical cases and materials related to that topic. The same topic was discussed during the bedside clinic and thestudent's observeddiagnostic and therapeutic procedures concerning that topic in their respective units.

At the end of 4 weeks the post test (same questions as pretest) was administered to all the students. The answers were corrected by 2 different examiners and scored for a maximum of 10 . They overall scores were categorized to poor $(<5)$ average $(5$ to 7$)$ and good $(>7)$.

The data was analyzed using the SPSS version 11. Gamma test and McNemer's tests were applied. P value of $<0.05$ was taken as statistically significant.

\section{Results}

Of the 250 students, 234 were included in the study. 16 of them were excluded due to absenteeism. In the pre-test 182 $(77.7 \%)$ of the students performed poorly, $52(22.3 \%)$ had average scores and none had good scores. In the post-test, only $21(8.97 \%)$ scored poorly, $159(67.9 \%)$ got average scores and $54(23.13 \%)$ got a good scores. (Table 1). There was a statistically significant improvement $(\mathrm{Gamma}=0.548, \mathrm{P}<0.001)$ in the number of students scoring average and good scores compared to the pre-test scores.

Table No1: Distribution of pre-test and post-test performance scores of students $(n=234)$.

\begin{tabular}{|l|l|l|}
\hline Score & Pertest (\%) & Post-test (\%) \\
\hline Poor & $182(77.7 \%)$ & $21(8.97 \%)$ \\
\hline Average & $52(22.3 \%)$ & $159(67.9 \%)$ \\
\hline Good & 0 & $54(23.13 \%)$ \\
\hline
\end{tabular}

Gamma $=0.548, \mathrm{P}<0.001$

Table No 2: Distribution of pre and post-test scores among various topics in Paediatrics.

\begin{tabular}{|l|l|l|l|l|l|}
\hline Specific topics & \multicolumn{2}{l|}{$\begin{array}{l}\text { Pre-test (n=234) } \\
\text { Rightwrong }\end{array}$} & \multicolumn{2}{l|}{$\begin{array}{l}\text { Post-test (n=234) } \\
\text { Rightwrong }\end{array}$} & P value \\
\hline Growth \&Anthropometry & 85 & 149 & 145 & 89 & $<0.001$ \\
\hline Development & 114 & 120 & 173 & 61 & $<0.001$ \\
\hline Nutrition & 112 & 122 & 165 & 69 & $<0.001$ \\
\hline New-born care & 52 & 182 & 138 & 96 & $<0.001$ \\
\hline Cardiology & 56 & 178 & 152 & 82 & $<0.001$ \\
\hline Respiratory & 71 & 163 & 136 & 98 & $<0.001$ \\
\hline Haematology & 62 & 172 & 114 & 120 & $<0.001$ \\
\hline GIT & 72 & 162 & 147 & 87 & $<0.001$ \\
\hline Socialpaediatrics & 64 & 170 & 129 & 105 & $<0.001$ \\
\hline Immunisation & 70 & 164 & 156 & 78 & $<0.001$ \\
\hline
\end{tabular}


The overall performance of students in post-test improved significantly ( $\mathrm{P}$ value $<0.001$ ) after the structured training in paediatrics for 1 month duration in all 10 subtopics (Table 2).

There was an average of 21 percent improvement in performance in the post-test vs pre-test scores, in the general paediatric topics of Growth \& Anthropometry, Development, and Nutrition. However, the improvement was 30 percent on an average, in systemic paediatric topics of cardiology respiratory, GIT except Haematology in which there was only a 20 percent improvement.

\section{Discussion}

India is home to $20 \%$ of global births and highest number of neonatal deaths in the world. High infant mortality and under five mortality is due to the inadequate child care practices, malnutrition and inadequate health care system. To improve the existing preventive and preventive health care system in children it is imperative that community physician has a proper training in common childhood ailments. It was with this background that paediatrics was recognised as a separate subject by MCI almost 15 years back [5]. But have we achieved it? The answer is a simple no.

As our classroom teaching methods have improved with the use of new teaching methods and teaching aids, we need to look into the traditional clinical teaching modules to make it more student centric and effective. We need to relook and improve our undergraduate clinical teaching so as to integrate various aspects of clinical medicine to expose students to a topic in its entirety. The traditional undergraduate teaching is not structured and students randomly encounter clinical cases and materials on various topics and subtopics during their clinical posting.

During this study, we decided to have a structured training program with maintaining a single topic as theme for a day for the final year undergraduates. Various aspects of the same topic was discussed in the general clinics, bedside clinics and therapeutics discussions along with procedures during ward rounds. As the various teaching modules had a common thread of a single topic, it helped the students stay focussed and reinforced their learning about that particular topic. The method of pre-test intervention and post-test was used here to assess the result of intervention [6].

This method has been tested by various authors and found to be very effective in assessing the success of the interventionat the end of the program $[6,7,8]$. In our study too we have analysed the performance of the students at the end of study and found that the structured training program resulted in significant improvement in all the 10 subtopics. The improvement was more pronounced in the systemic subtopics, which the students were not exposed to in the prior postings. To conclude, the theme based, structured training program incorporating the traditional modules of bed side case discussions along with the open forum of general clinic, therapeutics discussions and follow up during ward rounds along with exposure to diagnostic and therapeutic procedures resulted in significant improvement of the students knowledge in Paediatrics. Further studies are required to compare structured vs non structured undergraduate teaching program in order to prove its effectiveness and include case based scenarios and problem based learning $[9,10]$.

Funding: Nil, Conflict of interest: Nil

Permission from IRB: Yes

\section{References}

1. HillardR, Bannister Susan L, Amin Harishand Baird B. Paediatric medical education: challenges and new developments.Paediatrics and child health;b2009 may june: 14(5): 3030-309.

2. CleirhewL, RowneyDand Ker J. Stimulation in paediatric training. Archives of disease in childhood, Education and practice edition. 2016 Feb; 10(1): 8-14.

3. Thacker N. Medical Education - the Bottle necks, President's Page. Indian Paediatrics 2007; 44: 331-332.

4. Labrage G. Pre and post testing with more impact. Journal of Extension. 2007 Dec; .vol 45(6).

5. Guidelines for pre and post testing - a technical implementation guide. TIG 2:www.go2itech.org.

6. DauerL T, Kelvin JF, Horan CL and GermainJS. Evaluating the effectiveness of a radiation safety training intervention for oncology nurses: a pretest intervention - post-test study. BMC Medical Education 2006; 6:32. 
7. MuthukumarS,D'cruz S M, Anandarajan B. Introduction of Pre-Test and Post-Test enhances attentiveness to Physiology lectures - Students' perceptions in an Indian medical college. IJBAR 2013; 04 (05):341-344.

8. Barton R T, Dietz J T, and Holloway L. Using a Pretest- Posttest Design to Evaluate Continuing Education Programs Professional Development. The
International Journal of Continuing Social Work Education 2001;04: (1) 32 .

9. Jose $\mathrm{M}$ B and Buck E, Education and training journal. Sept 2013.

10. Donner RS, Bickley H .Bulletin of Medical library association, 1993. July 81(3). 294 -298.

\section{How to cite this article?}

D sa S, Pinto DJV, Bhat K. G, Baliga B. S, Joseph N. Effectiveness of a structured clinical program in paediatric undergraduate training. Int J Pediatr Res.2016;3(6):390-393.doi:10.17511/ijpr.2016.i06.04. 